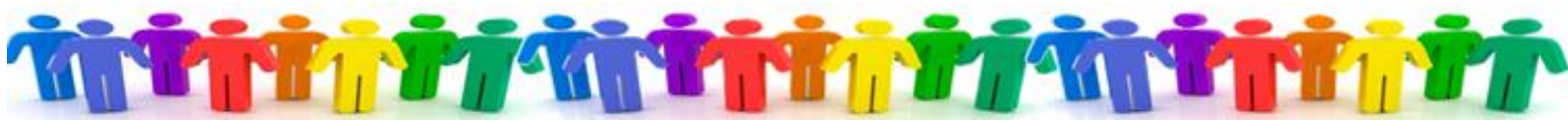

\section{The Perceived Awareness of the Research Hypothesis Scale: Assessing the Influence of Demand Characteristics}

\author{
Mark Rubin \\ The University of Newcastle, Australia
}

$15^{\text {th }}$ December 2016

Citation: Rubin, M. (2016). The Perceived Awareness of the Research Hypothesis Scale: Assessing the influence of demand characteristics. Figshare. doi: $\underline{10.6084 / \mathrm{m} 9 . \text { figshare.4315778 }}$

\begin{abstract}
The Perceived Awareness of the Research Hypothesis (PARH) scale is a 4-item quantitative self-report method for measuring the potential influence of demand characteristics in research situations. It can be used to help to refute the idea that observed effects are due to demand characteristics. The present article describes the PARH scale and discusses its advantages over other postexperimental feedback measures. Different approaches to analysing PARH data are considered. Finally, a survey of published research that has used the PARH scale shows that it has good internal reliability, and that it tends to show that research participants are not particularly aware of research hypotheses.
\end{abstract}

Keywords: demand characteristics; demand characteristics scale; research methodology; research artefacts; psychology

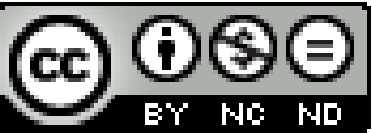

Copyright (C) The Author. OPEN ACCESS: This material is published under the terms of the Creative Commons Attribution-NonCommercial-NoDerivatives 4.0 International licence (CC BY-NC-ND 4.0; https://creativecommons.org/licenses/bync-nd/4.0/). This licence permits you to copy and redistribute this material in any medium or format for noncommerical purposes without remixing, transforming, or building on the material provided that proper attribution to the authors is given.

Correspondence concerning this article should be addressed to Mark Rubin at the School of Psychology, Behavioural Sciences Building, The University of Newcastle, Callaghan, NSW 2308, Australia. Tel: +61 (0)2 4921 6706. Fax: +61 (0)2 4921 6980. E-mail: Mark.Rubin@newcastle.edu.au Web: http://bit.ly/QgpV4O 
Demand characteristics are "the totality of cues which convey an experimental hypothesis to the subject" (Orne, 1962, p. 779). If participants are exposed to these cues and become aware of a study's research hypotheses, then they may respond in a way that they believe will confirm the hypotheses in order to be "good" participants and not "ruin" the research (Orne, 1962; for a review, see Strohmetz, 2008). Alternatively, they may attempt to sabotage the study by responding in ways that they believe will disprove the research hypotheses. Finally, they may respond in ways that they believe are socially desirable in the context of the proposed hypotheses. In all three cases, these unnatural responses compromise the ecological validity of the research, meaning that the research results may not generalize to more natural, real-world situations. Although researchers have been aware of this problem for over 50 years, the issue of demand characteristics continues to be a major source of concern (Sharpe \& Whelton, 2016).

In the present article, I consider Rubin, Paolini, and Crisp's (2010) Perceived Awareness of the Research Hypothesis (PARH) scale as a method for establishing the extent to which demand characteristics may be influential in research situations.

\section{The PARH Scale}

The PARH scale is a 4-item self-report measure that is usually presented near the end of a research study under the heading "Your thoughts about the research." The PARH items and instructions are as follows:

Please indicate how much you agree or disagree with each of the following statements:

1. I knew what the researchers were investigating in this research.

2. I wasn't sure what the researchers were trying to demonstrate in this research.

3. I had a good idea about what the hypotheses were in this research.

4. I was unclear about exactly what the researchers were aiming to prove in this research.

Participants respond to these items on a 7-point Likert-type scale ranging from strongly disagree (1) to strongly agree (7). Items 2 and 4 are reverse scored during coding, and the item scores are then averaged to form a single overall PARH score. Higher PARH scores indicate that participants believe that they are more aware of the research hypotheses.

\section{Advantages}

The PARH scale is a postexperimental feedback scale. However, it has a number of advantages over other postexperimental feedback scales. Some postexperimental feedback measures require research participants to describe the research hypotheses in response to prompts such as "what did you think this research was about?" The problem with this indirect approach is that participants may respond with vague and uninformative answers that reiterate information that the researchers have provided to them previously (e.g., "the research is a psychology study about person perception;" Page, 1973). In an effort to obtain more diagnostic responses, researchers may ask more direct questions such as "did you realise that the research was investigating prejudice against Muslims?" However, these more specific questions have the potential to reveal the research hypotheses to participants and result in false positive responses: Participants may indicate that they were aware of the hypothesis when, in fact, that awareness only occurred after reading the feedback questions (e.g., Berkowitz, 1971). The PARH scale strikes a balance between these 
two concerns: It asks direct questions about participants' awareness of the research hypotheses, but it does so without revealing what those hypotheses are (e.g., "I had a good idea about what the hypotheses were in this research").

The PARH scale is also innovative in its use of closed-ended items and a quantitative response format. This approach has four advantages. First, it is quicker and easier for participants to respond to closed-ended items that assess their understanding of the research hypothesis than it is for them to write about the actual hypotheses in an open-ended response format. In addition, there is likely to be less missing data using the PARH scale compared to an open-ended qualitative approach.

Second, it is quicker and easier for researchers to collate, analyse, and interpret the PARH scale's closed-ended quantitative data than it is for them to analyse and interpret the textual responses of the open-ended qualitative method.

Third, the PARH scale taps participants' implicit and intuitive understanding of the research hypotheses by asking about their perceived awareness of the research hypotheses without requiring them to state what the hypotheses are. Consequently, it provides a more subtle and sensitive measure than approaches that require participants to provide explicit descriptions of the research hypotheses. It is important to note here that the PARH scale cannot be used to establish whether or not participants are actually aware of the research hypotheses. It can only be used to assess the extent to which participants perceive that they are aware of the research hypotheses. Nonetheless, this perceived awareness may be used to establish the potential association between demand characteristics and observed research results.

Finally, the PARH scale's quantitative approach allows researchers to undertake statistical tests of the empirical associations between participants' perceived awareness of the research hypotheses and the measures that they use to test those hypotheses. I discuss four potential tests in the following section.

\section{Suggested Data Analyses}

Scores from the PARH scale can be used in a four ways to test the possibility that observed research results are influence by demand characteristics:

(1) Perform a one sample $\boldsymbol{t}$ test on the mean PARH score. Researchers can perform a one sample $t$ test on their sample's mean PARH score in order to test whether it is significantly different from the PARH scale's midpoint of 4.00. If their sample's mean PARH score is significantly below the scale midpoint or not significantly different from this midpoint, then researchers can claim that, in general, their participants reported feeling unclear about the research hypotheses.

(2) Exclude participants with a high PARH score. Positive outliers on the PARH scale (e.g., +3.00 standard deviations from the sample's mean PARH score) represent participants who are relatively confident that they are aware of the research hypotheses. Researchers can perform their statistical analyses with and without these PARH outliers in order to demonstrate that their general pattern of research results is unaffected by these participants' responses.

(3) Investigate associations between PARH scores and key variables. Researchers can perform correlation or regression analyses to investigate the associations between PARH scores and independent and/or dependent variable(s). Nonsignificant relationships between PARH scores and variable(s) of interest suggest that participants' reported awareness of the research hypotheses unrelated to their responses on these variable(s). 
(4) Include PARH scores as a covariate in analyses. Often the most informative analysis that researchers can undertake is to include mean PARH scores as a covariate in the analyses that demonstrate their key effects. If these key effects persist while controlling for PARH scores, then they are likely to occur over and above the influence of any demand characteristics.

Usage

The PARH scale is free to use and reproduce for research purposes. No permission is required. However, the scale may not be reproduced for commercial purposes.

Since its introduction in 2010 (Rubin et al., 2010), the PARH scale has been used in 13 published studies. My colleagues and I have used the PARH scale in seven of our published studies (Owuamalam, Rubin, \& Issmer, 2016; Meleady, Hopthrow, \& Crisp, 2013; Rubin, 2011; Rubin \& Paolini, 2014; Rubin, Paolini, \& Crisp, 2010, 2011, 2013). Several independent researchers have also used the PARH scale in six further studies published in journals such as the Journal of Experimental Social Psychology, Personality and Individual Differences, and the British Journal of Health Psychology (Fuchs, Schreier, van Osselae, 2015; Milner, Wagner, \& Crouch, 2016; Prior \& Sargent-Cox, 2014; Poon \& Chen, 2014; Stautz, Frings, Albery, Moss, \& Marteau, 2016; Su, 2014). These studies have included participants who have been recruited from Australia, the Netherlands, the UK, and the USA. Finally, several researchers have recommended the use of the PARH scale (Allen \& Smith, 2012; Ata, Thompson, \& Small, 2013; Morrison, Madden, Odum, Friedel, \& Twohig, 2014).

\section{Internal Reliability}

The 13 research studies cited above provide a total of 15 tests of the PARH scale's internal reliability. Based on this data, the Cronbach's alpha for the PARH scale items ranges from a minimum of .76 (Milner et al., 2016, Experiment 2) to a maximum of .93 (Wang et al., 2016, Study 2). The mean Cronbach alpha is .84 , which is above the conventional threshold value of .70.

\section{Mean and Standard Deviation}

The 13 research studies cited above provide 12 mean and standard deviation values for the PARH scale. Means range from a minimum of 2.91 (Rubin et al., 2010, Study 1) to a maximum of 4.23 (Milner et al., 2016, Experiment 2). The average mean value is $3.38(S D=.40)$, which is below the scale midpoint of 4.0. This mean value suggests that, on average, participants in the studies discussed above tended to disagree that they were aware of the research hypotheses.

The studies provided 11 standard deviation values that ranged from a minimum of 1.15 (Rubin, 2011) to a maximum of 1.62 (Wang et al., 2016, Study 2). The mean standard deviation is $1.34(S D=.13)$.

\section{Resources}

Please click here to download a hard copy of the scale for use in paper-and-pencil surveys. Please click here to download a Qualtrics .qsf file that you can import into the Qualtrics survey software platform. The file contains the PARH scale items that can be copied into Qualtrics surveys. 


\section{References}

Allen, A. P., \& Smith, A. P. (2012). Demand characteristics, pre-test attitudes and time-on-task trends in the effects of chewing gum on attention and reported mood in healthy volunteers. Appetite, 59, 349-356. doi: 10.1016/j.appet.2012.05.026

Ata, R. N., Thompson, J. K., \& Small, B. J. (2013). Effects of exposure to thin-ideal media images on body dissatisfaction: Testing the inclusion of a disclaimer versus warning label. Body Image, 10, 472-480. doi: 10.1016/j.bodyim.2013.04.004

Berkowitz, L. (1971). The "weapons effect", demand characteristics, and the myth of the compliant subject. Journal of Personality and Social Psychology, 20, 332-338. doi: $10.1037 / \mathrm{h} 0031804$

Fuchs, C., Schreier, M., \& van Osselaer, S. M. J. (2015) The handmade effect: What's love got to do with it? Journal of Marketing, 79, 98-110. doi: 10.1509/jm.14.0018

Meleady, R., Hopthrow, T., \& Crisp, R. J. (2013). Simulating social dilemmas: Promoting cooperative behavior through imagined group discussion. Journal of Personality and Social Psychology, 104, 839-853. doi: 10.1037/a0031233

Milner, J. S., Wagner, M. F., \& Crouch, J. L. (2016). Reducing child-related negative attitudes, attributions of hostile intent, anger, harsh parenting behaviors, and punishment through evaluative conditioning. Cognitive Therapy and Research, 1-19. doi: 10.1007/s10608-0169800-2

Morrison, K. L., Madden, G. J., Odum, A. L., Friedel, J. E., \& Twohig, M. P. (2014). Altering impulsive decision making with an acceptance-based procedure. Behavior Therapy, 45, 630-639. doi: 10.1016/j.beth.2014.01.001

Orne, M. (1962). On the social psychology of the psychology experiment: With particular reference to demand characteristics and their implications. American Psychologist, 17, 776 783. doi: $10.1037 / \mathrm{h} 0043424$

Owuamalam, C. K., Rubin, M., \& Issmer, C. (2016). Reactions to group devaluation and social inequity: A comparison of social identity and system justification predictions. Cogent Psychology, 3, 1188442. doi: 10.1080/23311908.2016.1188442

Page, M. M. (1973). On detecting demand awareness by postexperimental questionnaire. The Journal of Social Psychology, 91, 305-323. doi: 10.1080/00224545.1973.9923053

Poon, K. T., \& Chen, Z. (2014). When justice surrenders: The effect of just-world beliefs on aggression following ostracism. Journal of Experimental Social Psychology, 52, 101-112. doi: $10.1016 /$ j.jesp.2014.01.006

Prior, K., \& Sargent-Cox, K. A. (2014). Students' expectations of ageing: An evaluation of the impact of imagined intergenerational contact and the mediating role of ageing anxiety. Journal of Experimental Social Psychology, 55, 99-104. doi: 10.1016/j.jesp.2014.06.001

Rubin, M. (2011). Social affiliation cues prime help-seeking intentions. Canadian Journal of Behavioural Science, 43, 138-141. doi: 10.1037/a0022246

Rubin, M., \& Paolini, S. (2014). Out-group flies in the in-group's ointment: Evidence of the motivational underpinnings of the in-group overexclusion effect. Social Psychology, 45, 265-273. doi: $10.1027 / 1864-9335 / \mathrm{a} 000171$

Rubin, M., Paolini, S., \& Crisp, R. J. (2010). A processing fluency explanation of bias against migrants. Journal of Experimental Social Psychology, 46, 21-28. doi: $\underline{10.1016 / j . j e s p .2009 .09 .006}$ 
Rubin, M., Paolini, S., \& Crisp, R. J. (2011). The relationship between the need for closure and deviant bias: An investigation of generality and process. International Journal of Psychology, 46, 206-213. doi: 10.1080/00207594.2010.537660

Rubin, M., Paolini, S., \& Crisp, R. J. (2013). Linguistic description moderates the evaluations of counterstereotypical people. Social Psychology, 44, 289-298. doi: $\underline{10.1027 / 1864-}$ 9335/a000114

Sharpe, D., \& Whelton, W. J. (2016). Frightened by an old scarecrow: The remarkable resilience of demand characteristics. Review of General Psychology. doi: 10.1037/gpr0000087

Stautz, K., Frings, D., Albery, I. P., Moss, A. C., \& Marteau, T. M. (2016). Impact of alcoholpromoting and alcohol-warning advertisements on alcohol consumption, affect, and implicit cognition in heavy-drinking young adults: A laboratory-based randomized controlled trial. British Journal of Health Psychology. doi: 10.1111/bjhp.12221

Strohmetz, D. B. (2008). Research artifacts and the social psychology of psychological experiments. Social and Personality Psychology Compass, 2, 861-877. doi: 10.1111/j.1751-9004.2007.00072.x

$\mathrm{Su}$, L. (2014). Understanding psychological contract breach in the customer-firm relationship. Iowa State University Digital Repository. Retrieved from http://bit.ly/2huLyly

Wang, X., Chen, Z., Poon, K. T., Teng, F., \& Jin, S. (2016). Self-compassion decreases acceptance of own immoral behaviors. Personality and Individual Differences. doi: 10.1016/j.paid.2016.10.030

\section{Funding}

The author declares no funding sources.

\section{Conflict of Interest}

The author declares no conflict of interest. 